\title{
Performance evaluation of cutting fluids additives developed from recycling of polyethylene terephthalate
}

\author{
Nabel A. Negm ${ }^{1 \#}$, Nadia G. Kandile ${ }^{2}$, Ashraf M. Abd El Salam ${ }^{3}$ and Shady Atef \\ Mansour $^{3}$ \\ 1. Petrochemicals Department, Egyptian Petroleum Research Institute, Cairo, EGYPT. \\ 2. Chemistry Department, Faculty of Women, Ain Shams University, Cairo, Egypt. \\ 3. Research Center, Misr Petroleum Company, Cairo, Egypt.
}

\begin{abstract}
Metalworking-fluids (MWFs) perform essential functions to metal-products manufacturing industry. $M W F$ s also have inherent environmental and health liabilities associated to industry. These liabilities viewed as opportunity to reevaluate the functionality of MWFs and improve profitability of operations. Several problems appeared in using of MWFs including biodegradation of constituents. The objective of this study is to solve such problems by preparing additives for MWFs from recycling of polyethylene terephthalate polymer. This solves two critical problems which are: disposal of PET polymer, and decrease the bacterial degradation of MWFs. That improves stability of MWFs against biodegradation and increases the economic impact of MWFs.

Key Words: MWFs; tribological properties, metal processing, environment.
\end{abstract}

\section{Introduction}

Metal working oils is the name given to a range of oils and other liquids, it also called "cutting oils" that are used to cool and/or lubricate metal work pieces when they are being machined, ground, milled, etc. Historically, cutting fluids have been used extensively in metal cutting operations for the last 200 years. In the beginning, cutting fluids consisted of simple oils applied with brushes to lubricate and cool the machine tool [Holmes 1971; Watanabe et al., 1994]. Occasionally, lard, animal fat or whale oil was added to improve the oil's lubricity. As cutting operations became more severe, cutting fluid formulations became more complex. Today's cutting fluids are special blends of chemical additives, lubricants and water formulated to meet the performance demands of the metalworking industry. There are now several types of cutting fluids on the market, the most common of which can be broadly categorized as cutting oils or water-miscible fluids. Water-miscible fluids, including soluble oils, synthetics and semi-synthetics, are now used in approximately 80 to 90 percent of all applications [Stephenson and Agapiou, 1996; Astakhov, 2004]. Cutting fluids play a significant role in machining operations and impact shop productivity, tool life and quality of work. With time and use, fluids degrade in quality and eventually require disposal once their efficiency is lost. Cutting fluids are suffering from different changes occurred in their chemical structures due to the bacterial development [Herold et al. 1995; Bartz, 2001]. That is because some or all of their components are potential source of food and energy for these microorganisms. A suitable physical environment and a chemical environment which contains available carbon, nitrogen, phosphorus, sulphur, and many other elements in smaller amounts, are essential for microbial growth. The degradative processes must include energy-yielding reactions. The microbes live in the free water phase and hence can only live in straight cutting oil if it is contaminated with water. Thus cutting fluids are liable to suffer microbial attack, but there are, of course, thousands of different strains of microbes only a few of which are likely to be a significant hazard. The traditional method of controlling infection is by the use of biostats, which restrict microbial growth, and biocides, which actively kill microorganisms. Obviously a biocide added to an aqueous cutting fluid must be water soluble, and active at the $\mathrm{pH}$ and temperature of the system, against the types of microbes present. It must not be inactivated by the formulation components and in turn must not inactivate the formulation components. Its toxicity must present no hazards under the conditions of use and its odor and color must be acceptable [Hill, 1971; Silliman, 1992; Sluhan 1994]. In this study, we aim to decrease the disposal of polyethylene terephthalate polymer and convert it to additives for the cutting fluid formulations, with efficient biocidal activities against the growth of bacteria in these formulations.

Synthesis

\section{Experimental}

\section{Collection of PET Polymer}

The polymer was collected as waste products of water, cola drinks and other fabricates signed by PET label. Then the products were washed, grinded and packed for use. 


\section{Hydrolysis of PET Polymer}

PET (40 g) was charged in flat $500 \mathrm{ml}$ flask equipped with mechanical stirrer and thermometer. Then polyethylene glycol (40 g) with different molecular weight (400, 600 and $1000 \mathrm{~g} / \mathrm{mole}$ ) was added individually, and the reaction mixture was heated under stirring for 150 minutes. The product of the hydrolysis was then cooled and abbreviated as PET400, PET600 and PET1000 [Shukla et al. 2008]. In order to remove the unreacted glycol, excess distilled water was added to the glycolyzed products and the solution was vigorously stirred and then filtered. The water would dissolve any unreacted glycols and the most of the glycolyzed products precipitated out [Mansour and Ikladious, 2002], Scheme 1.

\section{Synthesis of Bromoacetate Derivatives}

A mixture of hydrolyzed PET (glycolyzed products) and bromoacetic acid was esterified in 1:1 molar ratio in $250 \mathrm{ml}$ xylene as a solvent and p-toluene sulfonic acid as a dehydrating agent in a dean-stark apparatus. The reaction end point was noticed when the calculated water of the reaction was obtained (1.8 $\mathrm{ml})$. Then the mixture was cooled and allowed to quaternization with excess amount of triethyl amine and pyridine individually. The obtained products were designated as PET400Br, PET600Br and PET1000Br [Negm and Aiad, 2007], Scheme 2.

\section{Synthesis of the Cutting Fluid Additives}

The quaternization was performed in acetone as a solvent and the reflux of the quaternization reaction was extended to 10 hours. After obtaining the desired quaternary products, the reaction matrix was cooled, filtered and washed twice by acetone and finally by petroleum ether. The obtained products were dried under vacuum and stored under desiccator. The obtained products were designated as PET400BrT, PET600BrT and PET1000BrT for triethyl amine derivatives and PET400BrPy, PET600BrPy, PET1000BrPy for pyridine derivatives, respectively [Negm and Mohamed, 2008].

\section{Application in cutting fluids additives Formulation}

The cutting fluids used in the study were two types; the first is the standard cutting fluid and the second is the formulated cutting fluid. The standard cutting fluid is formed of: base (mineral) oil (3.75 mL), emulsifier $(0.9 \mathrm{~mL})$, corrosion inhibitor $(0.5 \mathrm{~mL})(0.1 \%$ solution of CTAB in water), coupling agent $(0.1 \%$ solution of polyaminated fatty acid as secondary emulsifier and used to emulsify oil in water) (0.8 $\mathrm{mL})$ and biocide (Glokill-77=0.05 g/mL, formaldehyde-amine condensation product) and the remainder is water to complete the mixture to $100 \mathrm{~mL}$. The formulated cutting fluid is formed of: base (mineral) oil $(3.75 \mathrm{~mL})$, emulsifier $(0.9 \mathrm{~mL})$, corrosion inhibitor $(0.5 \mathrm{~mL})(0.1 \%$ solution of CTAB in water), coupling agent $(0.1 \%$ solution of polyaminated fatty acid as secondary emulsifier and used to emulsify oil in water) $(0.8 \mathrm{~mL})$ and the synthesized additives (PET400BrT, PET600BrT, PET1000BrT, PET400BrPy, PET600BrPy and PET1000BrPy) with different ratios $(0.05,0.025,0.0125,0.00625 \mathrm{~g} / \mathrm{mL})$ and the remainder is water to complete the mixture to $100 \mathrm{~mL}$.

\section{Instrumentation}

(a) Flash point measurements were performed using: Digital Electric Pensky-Martens, S.D.M. Apparecchi Scientifici Srl, Italy.

(b) Surface tension measurements were performed using: Du-Noüy tensiometer (Krüss type K6), Germany.

(c) Kinematic viscosity measurements were performed using: Tamson, model TV4000, Holland.

(d) Specific gravity measurements were performed using: KEM, model DA-640, Japan.

(e) $\mathrm{pH}$ value measurements were performed using: InoLab pH $720 \mathrm{WTW}$, Germany.

\section{Measurements}

The biological and tribological properties of the standard and formulated cutting fluids were evaluated using ASTM and IP standards.

\section{Kinematic Viscosity at $40{ }^{\circ} \mathrm{C}$ and $100{ }^{\circ} \mathrm{C}$}

It describes the viscosity of the cutting fluid formulation at $40{ }^{\circ} \mathrm{C}$ and $100{ }^{\circ} \mathrm{C}$ which is suitable for metal working at low and high temperatures of bending and twisting [ASTM D 445 2006].

\section{Specific Gravity}

It describes the workability of the cutting fluid formulation [ASTM D 4052, 2002]. The measurements procedures are as follow:

1- Introduce a small amount (about $0.7 \mathrm{~mL}$ ) of sample into the clean, dry sample tube of the instrument using a suitable syringe. 
2- The sample can also be introduced by siphoning. Plug the external TFE-fluorocarbon capillary tube into the lower entry port of the sample tube. Immerse the other end of the capillary in the sample and apply suction to the upper entry port using a syringe or vacuum line until the sample tube is properly filled.

3- Turn on the illumination light and examine the sample tube carefully. Make sure that no bubbles are trapped in the tube, and that it is filled to just beyond the suspension point on the right-hand side. The sample must be homogeneous and free of even the smallest bubbles.

4- After the instrument displays a steady reading to four significant figures for density, indicating that temperature equilibrium has been reached, record the density.

5- The recorded value is the final result, expressed either as density in $\mathrm{g} / \mathrm{mL}, \mathrm{kg} / \mathrm{m}^{3}$ or as relative density.

\section{Rust Prevention}

It describes the protection of the metal during processing using the cutting fluid formulations [ASTM D $665,2006]$. A mixture of $300 \mathrm{~mL}$ of the oil under test is stirred with $30 \mathrm{~mL}$ of synthetic sea water $(3.5 \mathrm{~g}$ $\mathrm{NaCl} / 100 \mathrm{~mL} \mathrm{H} \mathrm{H}_{2} \mathrm{O}$ ) at a temperature of $60 \pm 1{ }^{\circ} \mathrm{C}$ with a cylindrical copper test rod completely immersed therein. The test was repeated three times for $4 \mathrm{~h}$ and the test rod is observed for signs of rusting and the degree of rusting.

\section{Flash Point}

It describes the ability of the cutting fluid formulation to flash at the processing temperature $[I P 35$, 2001]. Thoroughly clean and dry all parts of the cup and its accessories. Remove all traces of solvent used to clean the apparatus. Fill the cup with the sample up to the level indicated by the filling-mark. Place the clip carrying the thermometer and test-flame on the cup, and set the latter in the stove. Ensure that the locating devices are properly engaged. Insert the thermometer. If it is known that the oil will flash above $104{ }^{\circ} \mathrm{C}$, use the IP $16 \mathrm{C}$ or ASTM 10C thermometer, otherwise, it is preferable to start with the IP 15C or ASTM 9C thermometer and change if a temperature of $104-110{ }^{\circ} \mathrm{C}$ is reached. Light the test-flame and adjust it so that it is of the size of a bead $4 \mathrm{~mm}$ in diameter. Apply heat at such a rate that the temperature recorded by the thermometer increases not less than $5{ }^{\circ} \mathrm{C}$ or more than $6{ }^{\circ} \mathrm{C} / \mathrm{min}$, and observe the surface of the oil carefully.

Open flash point is the point when a flash first appears at any point on the surface of the oil. Fire Point is the point at which the oil ignites.

\section{Viscosity Index}

It describes the flow tendency of the cutting fluid formulation in order to be efficient in removing the metal processing products $[A S T M D 2270,2004]$. The viscosity index (VI) is determined from the following equation:

where:

$$
\mathrm{VI}=[(\mathbf{L}-\mathrm{U}) /(\mathbf{L}-\mathbf{H})] \mathbf{x} 100
$$

$\mathbf{L}=$ kinematic viscosity at $40{ }^{\circ} \mathrm{C}$ of an oil of 0 viscosity index having the same kinematic viscosity at $100{ }^{\circ} \mathrm{C}$ as the oil whose viscosity index is to be calculated, $\mathrm{mm}^{2} / \mathrm{s}(\mathrm{cSt})$

$\mathbf{H}=$ kinematic viscosity at $40{ }^{\circ} \mathrm{C}$ of an oil of 100 viscosity index having the same kinematic viscosity at $100{ }^{\circ} \mathrm{C}$ as the oil whose viscosity index is to be calculated $\mathrm{mm}^{2} / \mathrm{s}(\mathrm{cSt})$

$\mathbf{U}=$ kinematic viscosity at $40^{\circ} \mathrm{C}$ of the oil whose viscosity index is to be calculated $\mathrm{mm}^{2} / \mathrm{s}$ (cSt).

pH

It describes the nature of the cutting fluid formulation and its ability to cause rust or corrosion to the metal surface.

\section{Emulsification Power}

It describes the stability of the components which form the cutting fluid formulation and their ability to be homogeneous during application and storage [IP 263, 1994].

\section{Surface Tension}

It describes the surface spreading of the cutting fluid formulation on the metal surface in term of surface tension value. Surface tension data $(\gamma)$ of the synthesized additives were measured by Du-Noüy tensiometer (Krüss type K6) (Hamburg, Germany) using platinum ring detachment method and was calibrated by deionized water at 25 ${ }^{\circ} \mathrm{C}$. The surface tension measurements were taken after 1 minute of pouring the solution in the measuring cup to ensure the equilibrium $[A S T M D 1331,2011]$.

\section{Antimicrobial Evaluation}

\section{Growing of Microorganisms}

The bacterial strains were cultured according to standards of the National Committee for Clinical Laboratory (NCCLS) [National Committee for Clinical Laboratory Standards 1997]. The bacterial species grow on nutrient agar. The nutrient agar medium consisted of Beef extract $(3.0 \mathrm{~g} / \mathrm{L})$, Peptone $(5.0 \mathrm{~g} / \mathrm{L})$, Sodium chloride $(5.0$ 
$\mathrm{g} / \mathrm{L})$, Agar $(20.0 \mathrm{~g} / \mathrm{L})$; then the volume was completed to one liter distilled water, the mixture heated until boiling and the media sterilized by autoclave. The bacterial strains were kept on nutrient agar medium and showed no inhibition zones.

\section{Measurements of Resistance and Susceptibility}

For preparation of discs and inoculation, $1.0 \mathrm{~mL}$ of inocula were added to $50 \mathrm{~mL}$ of agar media and mixed. The agar was poured into $120 \mathrm{~mm}$ petri dishes and allowed to cool to room temperature. Wells $(6 \mathrm{~mm}$ in diameter) were cut in the agar plates using proper sterile tubes and filled up to the surface of agar with $0.1 \mathrm{~mL}$ of the synthesized cationic additives dissolved in PEG $(1,2,5 \mathrm{mg} / \mathrm{ml}$ PEG). The plates were left on a leveled surface, incubated for $24 \mathrm{~h}$ at $30{ }^{\circ} \mathrm{C}$ and then the diameters of the inhibition zones were read. The inhibition zone formed by these compounds against the particular test bacterial strain determined qualitatively the antibacterial activities of the synthetic compounds. The mean value obtained for three individual replicates was used to calculate the zone of growth inhibition of each sample. The antimicrobial activity was calculated as a mean of three replicates. The tested compounds were completely compatible with the medium of agar and no turbidity was observed during the mixing process [National Committee for Clinical Laboratory Standards 1997; Negm et al., 2010].

\section{Structure}

\section{Results And Discussion}

The chemical structures of the prepared additives and the intermediates were confirmed using IR and ${ }^{1}$ HNMR spectroscopy. The glycolysed intermediates PET400, PET600 and PET1000 showed IR absorption bands at (PET600 taken as representative sample, Figure 1): $3100-3500 \mathrm{~cm}^{-1}$ centered at $3400 \mathrm{~cm}^{-1}$ characteristic for hydroxyl group, $2873 \mathrm{~cm}^{-1}$ for stretching of $\mathrm{CH}_{2}$ groups, $1718 \mathrm{~cm}^{-1}$ of the carbonyl groups, $1109 \mathrm{~cm}^{-1}$ of ether linkage, $950-870 \mathrm{~cm}^{-1}$ of phenyl groups. ${ }^{1} \mathrm{HNMR}$ spectra showed signals at: 8.0, 4.9, 3.5, 3.3 and 2.4 ppm corresponding to hydroxyl, phenyl, $\left(\mathrm{COOC}_{2} \mathrm{CH}_{2} \mathrm{O}\right),\left(\mathrm{COOCH}_{2} \mathrm{CH}_{2} \mathrm{O}\right),\left(\mathrm{C}_{2}\right)_{\mathrm{n}}$, Fig. 2.

The bromoacetyl intermediates PET400Br, PET600Br and PET1000Br showed IR absorption bands identical absorption bands for PET400, PET600 and PET1000, and also anew absorption band was reported at $650 \mathrm{~cm}^{-1}$ corresponds to the C-Br stretching, Fig. 3. While the ${ }^{1} \mathrm{HNMR}$ spectra showed the characteristic signal at 4.0 ppm as an indication for the bromo-substitution, Fig. 4.

The obtained quaternary ammonium derivatives PET400BrT, PET600BrT, PET1000BrT, PET400BrPy, PET600BrPy and PET1000BrPy showed a characteristic absorption band at $3060 \mathrm{~cm}^{-1}$ characteristic for the quaternary nitrogen $\left(\mathrm{N}^{+}\right)$, Figs. 5-6. While the ${ }^{1} \mathrm{HNMR}$ spectra showed the distribution of the protons, Figs. 7-8. From the above data of IR and ${ }^{1}$ HNMR spectra, the chemical structures of the obtained intermediates and the cationic surfactants were confirmed as represented in Schemes 1-3.

\section{Evaluation of the Additives}

In order to evaluate the synthesized additives as biocides to prevent the potential effect of microorganisms on the constituents of the cutting fluids formulations, two evaluation steps were preceded. The first was the biocidal activity assay of these additives against the microorganisms in the cutting fluids. The second was the tribological properties of the cutting fluids.

\section{The Biocidal Activity Assay}

The biocidal activity of the synthesized additives was evaluated using freshly prepared cutting fluid contaminated with bacteria in presence of the $0.5-1 \%$ of the different additives. The results of the biological activities of the biocides in the contaminated cutting fluids were listed in (Table 1).

The number of colonies in the untreated sample was too much to be counted. That was accompanied by the turbidity appearance in the sample after two days with unacceptable odor and starts to separate into two layers. The treated samples with the different biocides showed stability in appearance, color, homogeneity and odor. The biocidal activities of the different additives were measured at different concentrations. The obtained MIC values were $0.5 \%$ for all of the different additives. The data of the biocidal activity were considered at different concentrations. But to determine the exact concentration which will be suitable as an efficient additive, the results of the tribological properties were considered.

\section{Tribological Properties}

The tribological properties of the cutting fluids formulated with the synthesized additives (PET400BrT, PET600BrT, PET1000BrT, PET400BrPy, PET600BrPy and PET1000BrPy) were compared by the standard cutting fluid formulated with the commercial additive of commercial biocides, corrosion inhibitor and emulsifier. 


\section{Kinematic Viscosity}

The kinematic viscosity represents the viscosity of the cutting fluid formulation and the retaining of the viscous structure of the formulation at different temperatures. The viscosity retaining is very important as a characteristic of the cutting fluid. Viscous fluids have ability to form film on the metal fabricates during processing, therefore, cooling and lubricating efficiency increased. Furthermore, increases the life time of the tools and machines.

The kinematic viscosities at $40{ }^{\circ} \mathrm{C}$ and at $100{ }^{\circ} \mathrm{C}$ of the standard cutting fluid were 32.87 and 5.39 $\mathrm{mm}^{2} / \mathrm{s}$ (cSt). The addition of the synthesized additives at different ratios of: $0.1,0.25,0.5$ and $1 \%$ has no change on the kinematic viscosities of the formulated cutting fluids at $40{ }^{\circ} \mathrm{C}$ and $100{ }^{\circ} \mathrm{C}$ considerably. The change of these two values was in the range of $0.1-0.2 \mathrm{~mm}^{2} / \mathrm{s}(\mathrm{cSt})$. The relative stability of the viscosity of the cutting fluids at these two temperatures in the presence of the different additives showed their validity in the formulation of cutting fluid formula.

\section{Specific Gravity}

The specific gravity is the second parameter which monitored in the cutting fluid formulation. The specific gravity shows the workability of the cutting fluid formulation in the cutting or twisting processes of the metals. Increasing the specific gravity of the cutting fluid increases the torsion on the machines, which may causes damage to the working tools. The specific gravity of the standard cutting fluid is $0.911 \mathrm{~g} / \mathrm{ml}$. The addition of the different additives at different concentrations has no effect on the specific gravities of the formulated cutting fluids. That indicates the suitability of these additives and the lake of diverse in their presence in the formulation.

\section{Flash Point}

The flash point of the cutting fluid is the third parameter described the ability of the cutting fluid to flash in the open air under the influence of the heat. During the metal processing, temperature is increased considerably due to the friction of the metal surface by the cutting and machining tools. The increase of temperature can produce flame, which is responsible for the fire. The additives of the cutting fluids are suitable when they don't decrease their flash points. The flash point of the cutting fluid is $195{ }^{\circ} \mathrm{C}$. The addition of the different additives at different concentrations is quietly changed the flash points of the different formulations. The change of the flash points was in the range of $1-2{ }^{\circ} \mathrm{C}$, which can be considered in the safe side of the flash point variation.

\section{Rust Prevention}

Corrosion of the metallic fabricates after the manufacture is mainly happened due to the interaction of the metal by the oxygen. It is important to protect the metal fabricates after fabrication, which is achieved by the use of the corrosion inhibitors in the chemical formulation of the cutting fluids. Therefore, cutting fluids must contain corrosion inhibitors to prevent rust formation during the processing. Rust protection or corrosion inhibition tendency of the cutting fluids towards copper strips is the fourth important parameter characterizes the applicability of the cutting fluids. The standard cutting fluid showed no rust or corrosion products formation after the immersion of copper strip for 3 days. On the other hand, the addition of the different additives at different concentrations showed stabilization of the copper strip, either rust or corrosion products formation. That showed the ability of these additives to prevent rust of metallic fabricates when used in the formulation of the cutting fluids.

\section{Viscosity Index}

The viscosity index is a parameter describes the fluidity of the cutting fluid during processing. This factor is very important because high viscosity index formulations cannot cover the entire metal surface during the fabrication processes. That leads to increase the temperature of the machines and fabrication tools, which consequently decreases their lifetimes. The viscosity index of the standard cutting fluid is 96 , which did not change after the addition of the different additives to the cutting fluids at the entire range of concentration.

pH

The acidity of the cutting fluid is determined in term of $\mathrm{pH}$. The cutting fluid is generally alkaline to prevent the corrosion of the metal fabricates. The standard cutting fluid has a $\mathrm{pH}$ value of 9 . The addition of the cutting fluid additives did not alter the $\mathrm{pH}$ of the formulated cutting fluid, i.e., remained at 9.

\section{Emulsification Power}

The cutting fluid formulation, as represented above, is simply an emulsion of oil and water. The stability of that emulsion is a key phenomenon which determined the applicability of the cutting fluid. The 
emulsification power is determined the stability of the cutting fluid after certain time. Decreasing the emulsion stability of the cutting fluid leads to separation of the oil and water into two layers. The formulated cutting fluids with the synthesized additives showed two different behaviors depending on the concentration of each additive. At lower additives concentrations of 0.1 and $0.25 \%$, the emulsion stabilities of the cutting fluids were very high and there was no turbidity in the formula after 14 days. But, increasing the concentration of the additives to 0.5 and $1 \%$ decreases the emulsion stability of the formula to 7 days. Finally, increasing the concentration of the additives to more than $1 \%$ showed sharp dropdown in the emulsion stability of the cutting fluid formulation to less than 2 days.

\section{Conclusions}

From the results obtained in this study we can reach to the following conclusions:

1. The recycling of polyethylene terephthalate can produce efficient additives to the cutting fluid formulation without changing the tribological properties of these formulations according to the ASTM and IP standards.

2. Increasing the ratio of the synthesized additives has no effect on several properties of the cutting fluids including: viscosity, specific gravity, flash point, rust prevention, viscosity index and $\mathrm{pH}$.

3. The maximum additives concentration which has no effect on the stability of the cutting fluid formulation is $1 \%=0.05 \mathrm{ml}$.

4. The additives have excellent biocidal activity against bacterial growth in cutting fluids, so these compounds can be used as efficient biocides for preventing bacterial growth in cutting fluid.

\section{References}

[1]. Astakhov VE, 2004, The assessment of cutting tool wear. Int. J. Machin. Tool Manuf, 44:637-647.

[2]. ASTM D 1331, 2011, Standard Test Methods for Surface and Interfacial Tension of Solutions of Surface-Active Agents

[3]. ASTM D 2270, 2004, Standard Practice for Calculating Viscosity Index from Kinematic Viscosity at $40^{\circ} \mathrm{C}$ and $100^{\circ} \mathrm{C}$.

[4]. ASTM D 4052, 2002, Standard Test Method for Density and Relative Density of Liquids by Digital Density Meter.

[5]. ASTM D 445, 2006, Standard Test Method for Kinematic Viscosity of Transparent and Opaque Liquids.

[6]. ASTM D 665, 2006, Standard Test Method for Rust-Preventing Characteristics of Inhibited Mineral Oil in the Presence of Water.

[7]. Bartz W, 2001, Ecological and Environmental Aspects of Cutting Fluids. Lub. Eng, 57:13-16.

[8]. Herold CH, Limia JM, Steber J, 1995, Comparative evaluation of anaerobic biodegradability of hydrocarbons and fatty derivatives currently used as drilling fluids. Chemosphere, 31:3105-3118.

[9]. Hill EC, 1971, Microbial Infections in Relation to Corrosion during Metal Machining and Deformation. In Microbial Aspects of Metallurgy, Med. Tech. Pub, 5:129-155.

[10]. Holmes PM, 1971. Factors Affecting the Selection of Cutting Fluids. Ind. Lubr. Tribol, 2:47-55.

[11]. IP 263, 1994, Determination of Stability of Water Mix Metal Working Fluids.

[12]. IP 35, 2001, Determination of Open Flash and Fire Point. Pensky-Martens Method.

[13]. Mansour SH, Ikladious NE, 2002, Depolymerization of poly(ethylene terephthalate) wastes using 1,4-butanediol and triethylene glycol. Polym. Test, 21:497-505.

[14]. National Committee for Clinical Laboratory Standards 1997, Methods for dilution antimicrobial susceptibility tests for bacteria that grow aerobically. Approved standard M7-A4, Wayne.

[15]. Negm NA, Aiad IA, 2007, Synthesis and Characterization of Multifunctional Surfactants in Oil-Field Protection Applications. J. Surfact. Deterg, 10:87-92.

[16]. Negm NA, Aiad IA, Tawfik SM, 2010, Screening for potential antimicrobial activities of some cationic uracil biocides against wide spreading bacterial strains. J. Surfact. Deterg, 13:503-511.

[17]. Negm NA, Mohamed AS, 2008, Synthesis, Characterization and Biological Activity of Sugar-Based Gemini Cationic Amphiphiles. J. Surfact. Deterg, 11:215-221.

[18]. Shukla SR, Harad AM, Jawale LS, 2008, Recycling of waste PET into useful textile auxiliaries. Waste Manag, 28:51-60.

[19]. Silliman JD, Perich R, 1992, Cutting and Grinding Fluids: Selection and Application, Second Edition. Dearborn, Michigan: Society of Manufacturing Engineers.

[20]. Sluhan CA 1994, Selecting the Right Cutting and Grinding Fluids. Tool Prod.

[21]. Stephenson DA, Agapiou JS, 1996, Metal Cutting Theory and Practice. Marcel Dekker, New York.

[22]. Watanabe S, Nakagawa H, Ohmori Y, Fujita T, Sakamoto M, 1994, Characteristic Properties of Cutting Fluid Additives Derived from the Derivatives of Ricinoleic Acid Polymers. J. Am. Oil. Chem. Soc., 71:1003-1006.

Table 1: The results of the biological activities of the biocides in the contaminated cutting fluids

\begin{tabular}{|c|c|c|c|}
\hline Samples & $\begin{array}{c}\text { Minimum Inhibitory } \\
\text { Concentration, (MIC) }\end{array}$ & $\begin{array}{c}\text { Bacterial Colonies } \\
\text { Count, (BCC) }\end{array}$ & $\begin{array}{c}\text { Efficiency of } \\
\text { additive (\%) }\end{array}$ \\
\hline Standard & ------ & Too many to be counted & ------ \\
\hline PET400BrT & $0.5 \%=0.025 \mathrm{ml}$ & No visible growth & About $100 \%$ \\
\hline PET600BrT & $0.5 \%=0.025 \mathrm{ml}$ & No visible growth & About $100 \%$ \\
\hline PET1000BrT & $0.5 \%=0.025 \mathrm{ml}$ & No visible growth & About $100 \%$ \\
\hline PET400BrPy & $0.5 \%=0.025 \mathrm{ml}$ & No visible growth & About $100 \%$ \\
\hline PET600BrPy & $0.5 \%=0.025 \mathrm{ml}$ & No visible growth & About $100 \%$ \\
\hline PET1000BrPy & $0.5 \%=0.025 \mathrm{ml}$ & No visible growth & About $100 \%$ \\
\hline
\end{tabular}




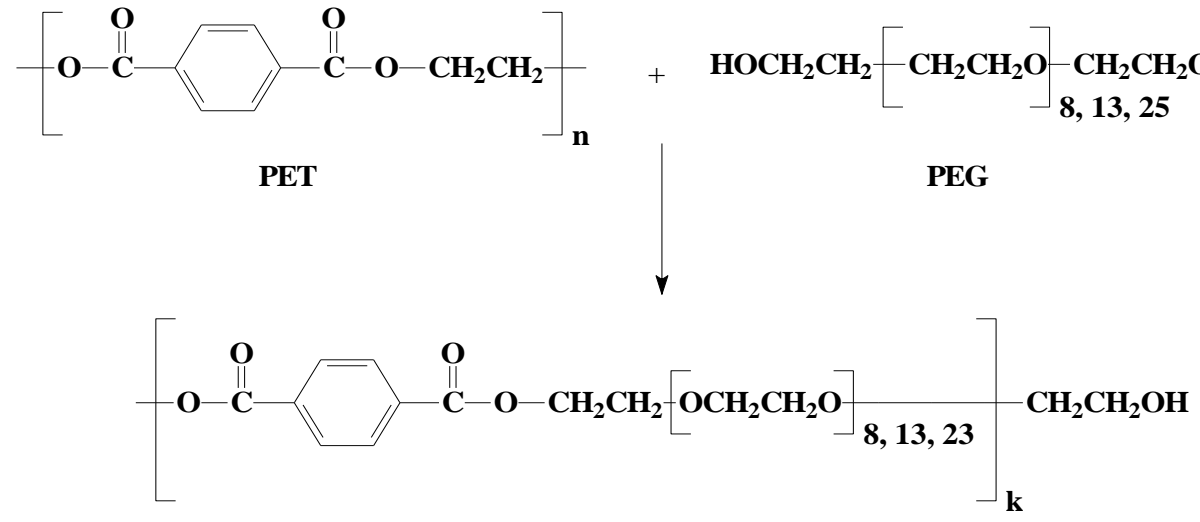

Glycolyzed PET

Scheme 1: Glycolysis of PET.

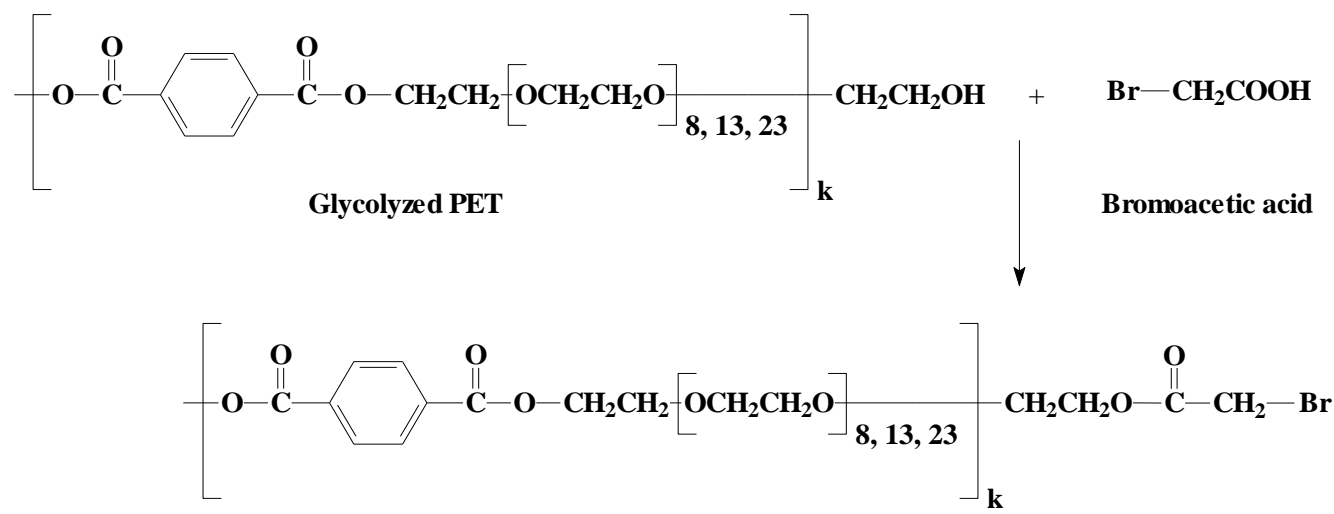

Glycolyzed PET bromoacetate derivatives

Scheme 2: Synthesis of glycolyzed PET bromoacetate derivatives.

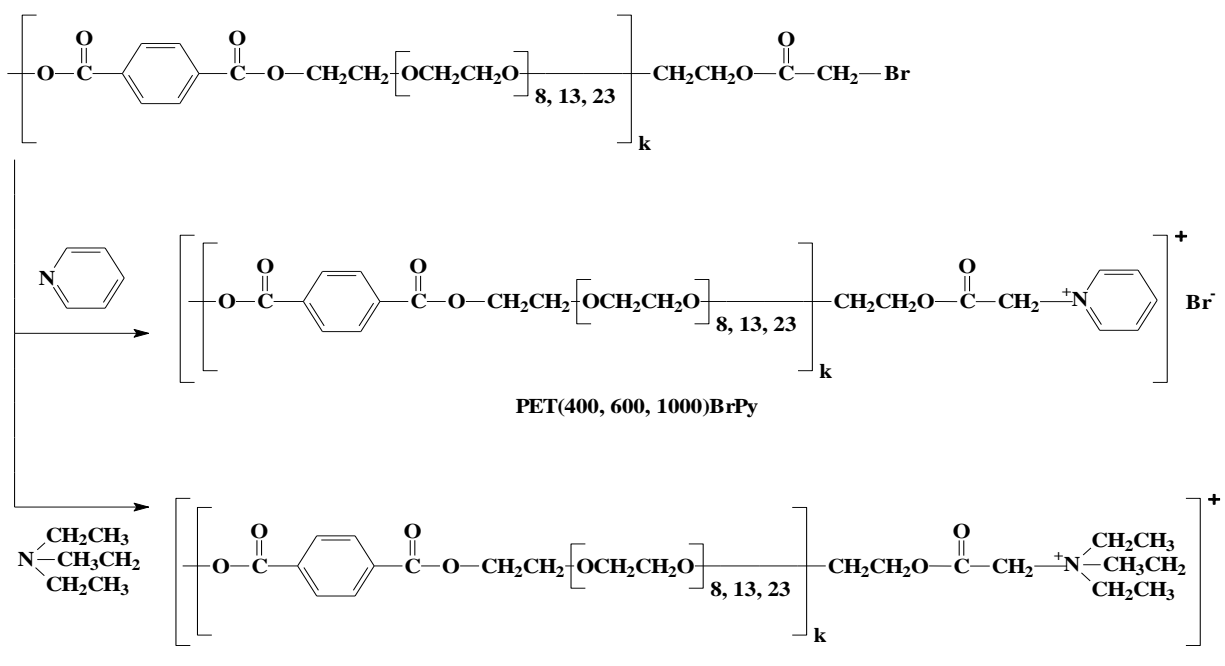

PET $(400,600,1000) B r T$

Scheme 3: Synthesis of cationic surfactants, PET400BrT, PET600BrT, PET1000BrT PET400BrPy, PET600BrPy and PET1000BrPy. 


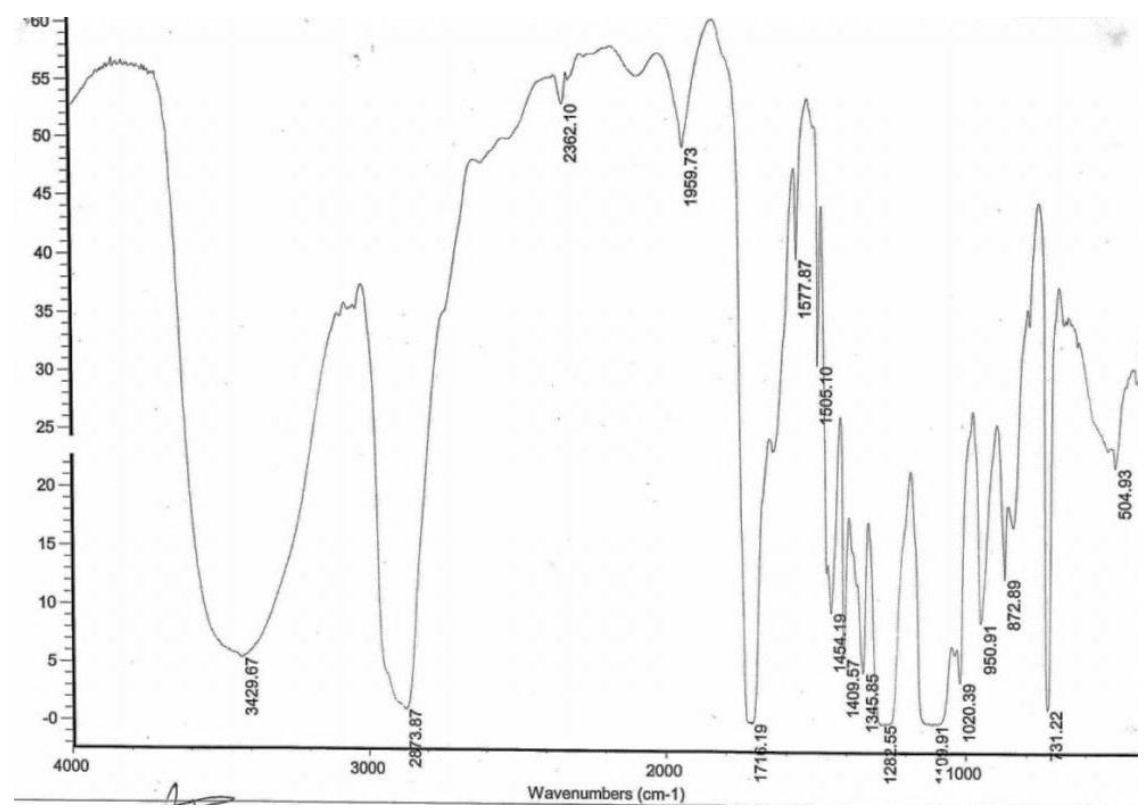

Figure 1: IR spectra of PET600

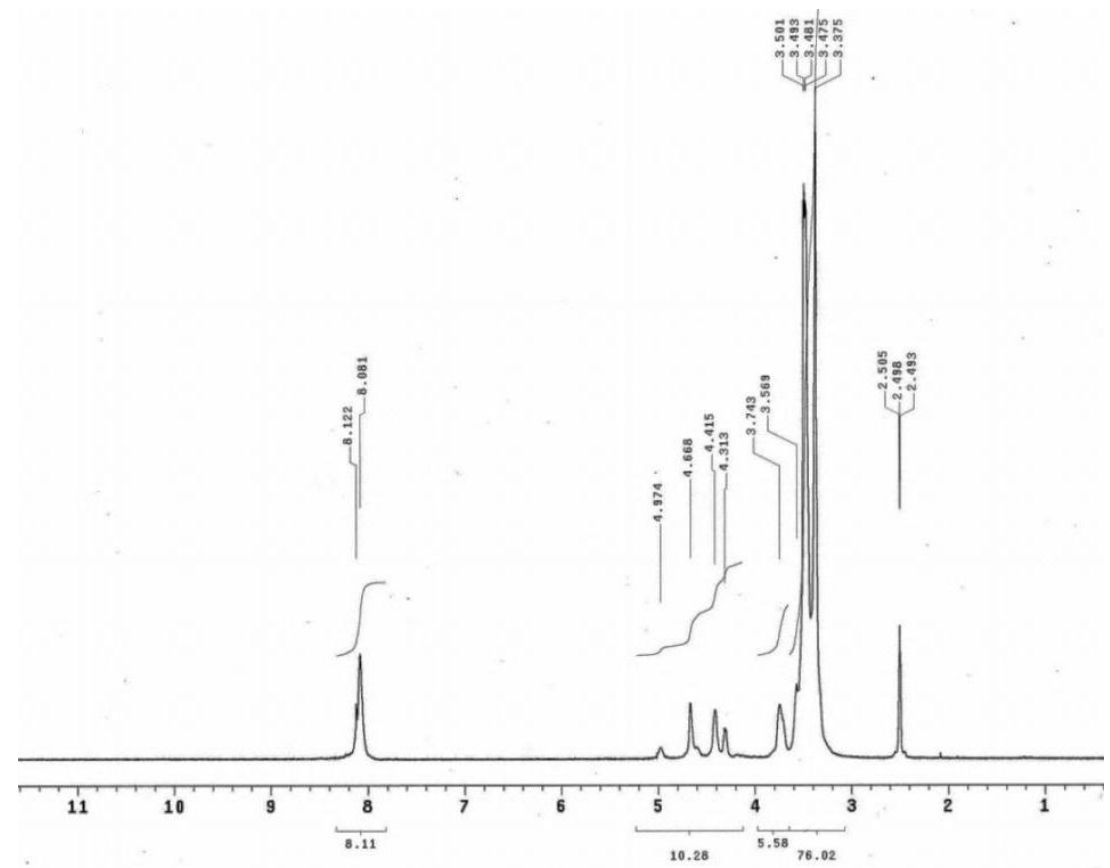

Figure 2: ${ }^{1} \mathrm{HNMR}$ spectra of PET600. 


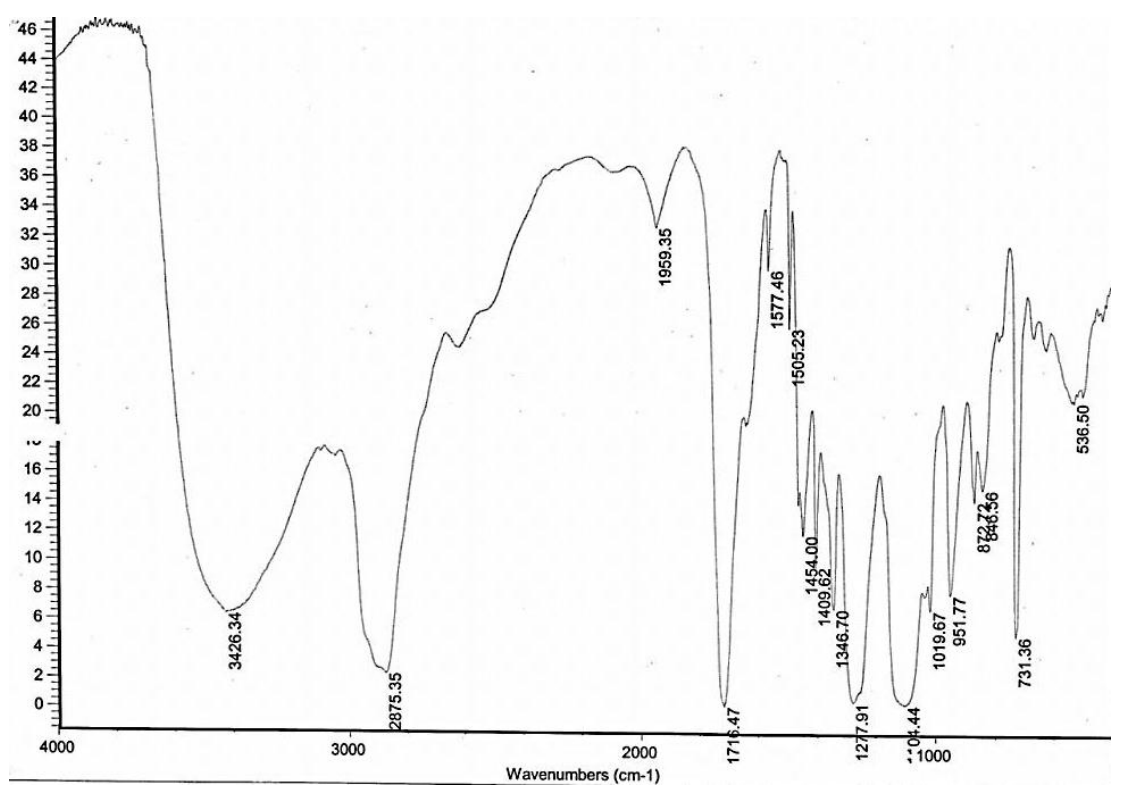

Figure 3: IR spectra of PET600Br.

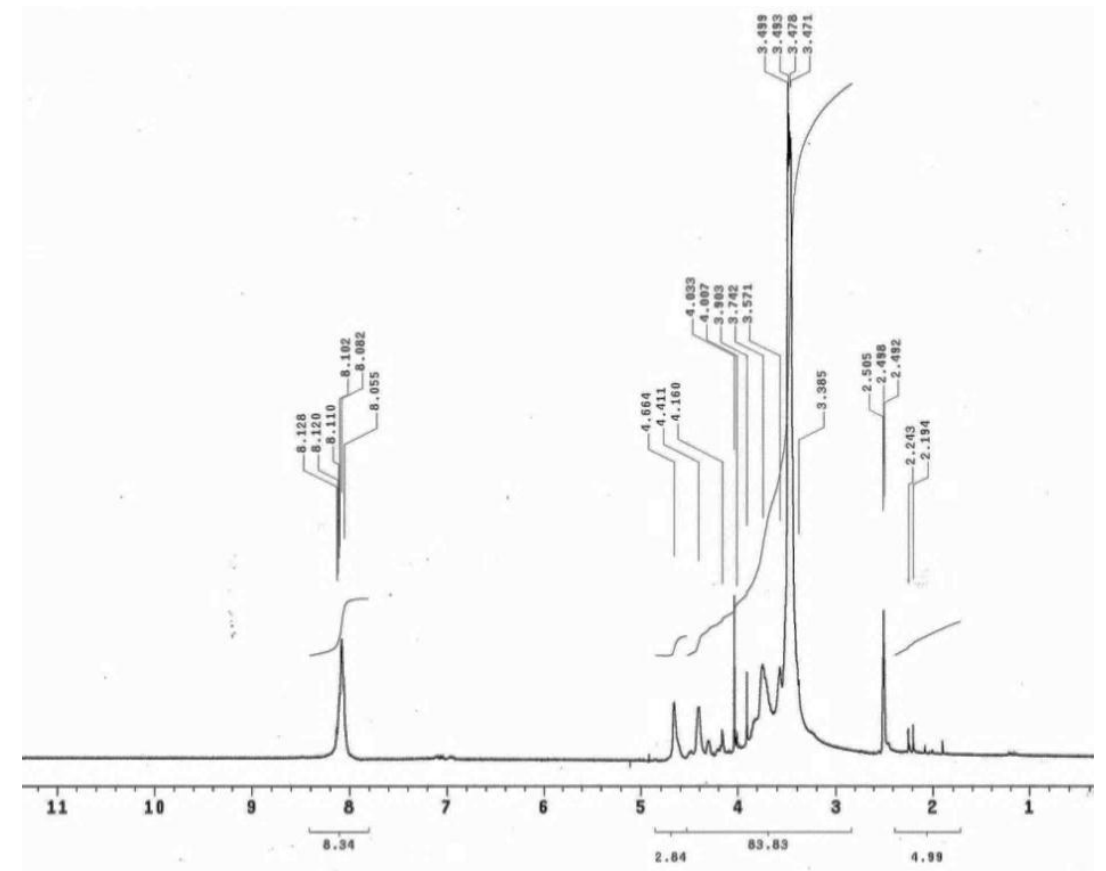

Figure 4: ${ }^{1} \mathrm{HNMR}$ spectra of PET600Br. 


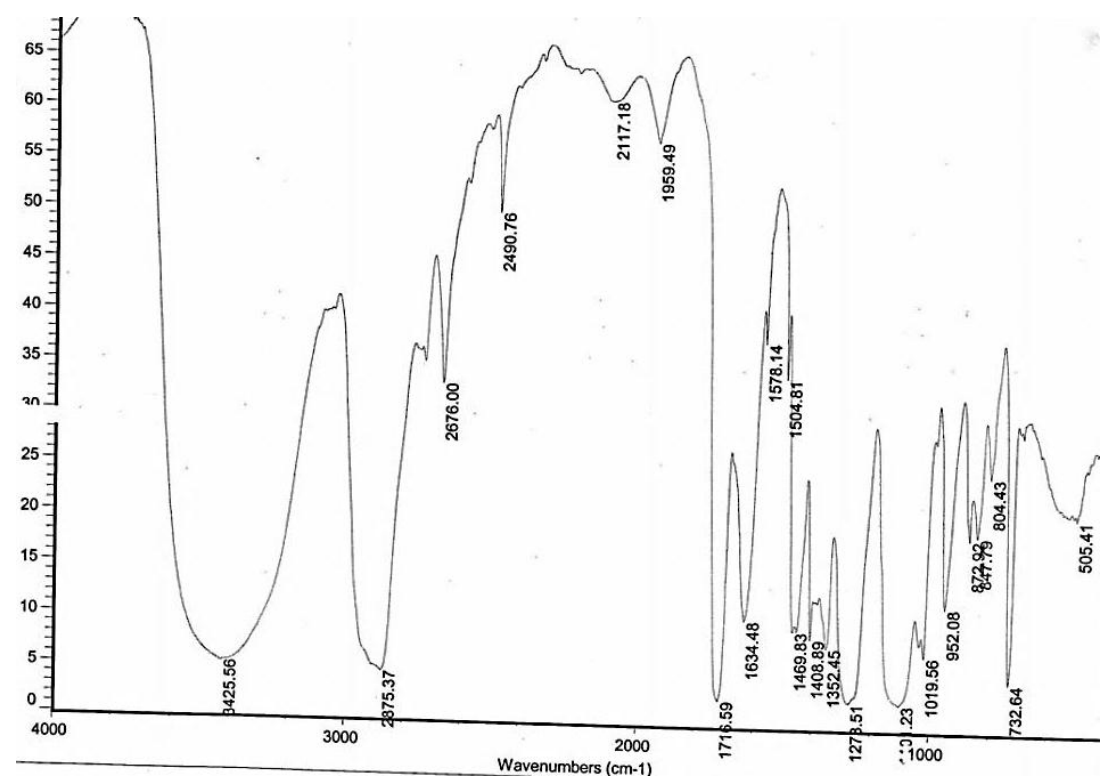

Figure 5: IR spectra of PET600BrT.



Figure 6: ${ }^{1}$ HNMR spectra of PET600BrT. 


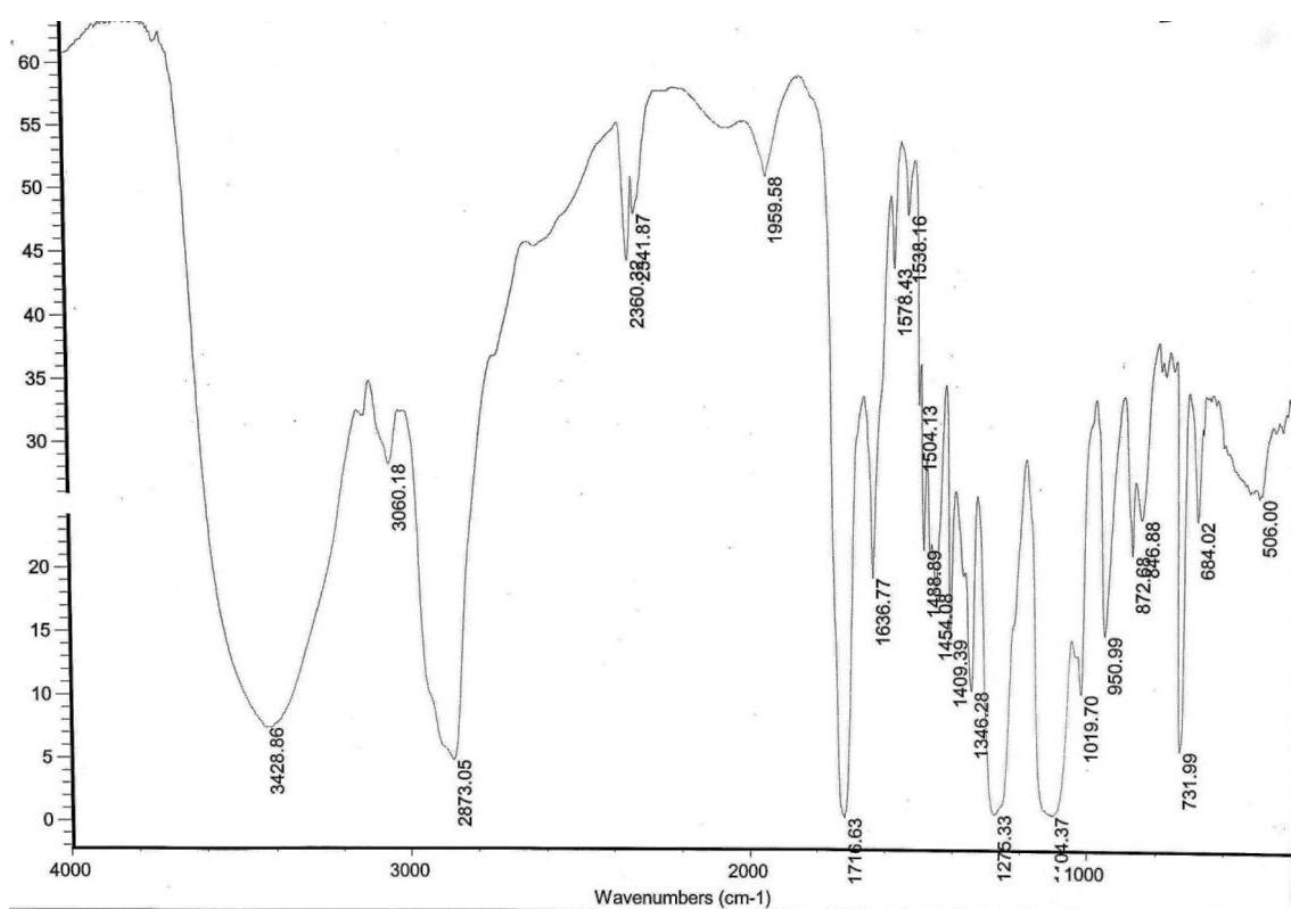

Figure 7: IR spectra of PET600BrPy.

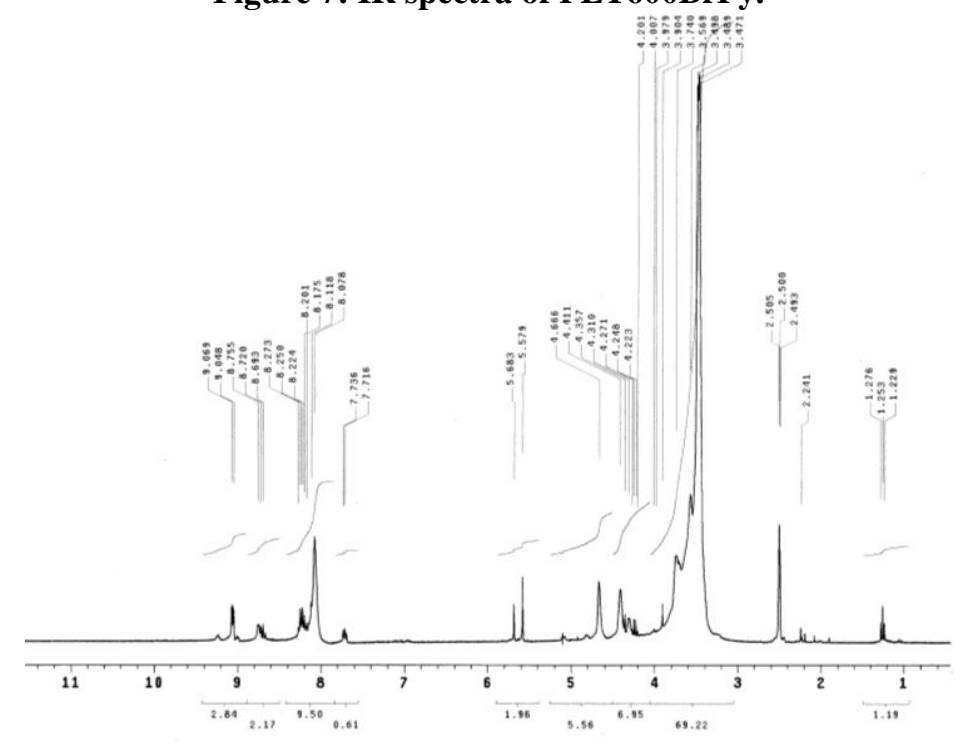

Figure 8: ${ }^{1}$ HNMR spectra of PET600BrPy. 